and many of the more rare clinical syndromes. Most of the hypotheses are supported by credible logic, but there are occasional lapses into such emotive statements as "the inadequate surgeon does not belong in the operating room. He should restrict his manipulations to the intact globe".

A suitable proportion of the text is devoted to a detailed description of surgical techniques.

The book is well illustrated and is thoroughly recommended as a book of reference for clinical problems related to the vitreous.

Facial Injuries. By R. G. Schultz. I970. Pp. 264, I 74 figs. Year Book Medical Publishers, Chicago; Wiley, Chichester. (1 $36 s$.

A well-illustrated, well-produced book, but one which is not intended for ophthalmic surgeons. Indeed the ocular signs, where relevant, are poorly described.

\title{
Notes
}

\section{Ophthalmological Society of the United Kingdom}

\author{
9oth Annual Congress, April 1970
}

The goth Annual Congress of the Ophthalmological Society of the United Kingdom, held at Churchill College, Cambridge, on April 6-8, 1970, under the presidency of Mr. T. Keith Lyle departed from the pattern of its predecessors. There were some sixteen "free papers" and two symposia, but there was also an afternoon of seminars.

These seminars, twelve in number, had a chairman and three panellists, and up to 25 members of the Congress could attend each seminar which lasted I 1 hours. There were thus two sessions in the afternoon separated by a tea interval. The subjects included "Management of palsy of traumatic origin", "Simple glaucoma", "Modern techniques in retinal detachment", "Pallor of the disc", "Herpes simplex", "Iatrogenic ocular disease", "Recent trends in prosthetics, implants, and contact lenses", "Retinal vascular disease", "Retinal neoplasm", "Recent trends in corneal transplantation", "Complicated lacrimal obstruction", and "Modern therapy of uveitis". The layout at Churchill College was ideal for this type of session which seemed very popular with the members, but it seems unlikely that this could be repeated at the Royal College of Physicians, London, as the required number of rooms would not be available. Though, because of the time taken up by the symposia and seminars, there were only sixteen "free papers", these were all of a high standard introducing new ideas.

Mr. J. C. Mustardé discussed the surgical approach to tumours of the eyelid. He emphasized that the upper lid should not be used to make up defects of the lower lid. He described a method of reconstructing the lower lid by rotation of a cheek flap lined with a composite graft of nasal septal mucosa and cartilage, and of reconstructing the upper lid by using a switch flap taken from the lower lid.

Dr. Charles D. Kelman flew from New York to read his paper on "Phaco-emulsification"; a film showing this technique was accompanied by his own music! In this technique the lens matter is aspirated through a 2-mm. incision at the limbus. A high-frequency needle surrounded by a protective silicon sleeve emulsifies the lens matter which is removed by suction with a flow of fluid.

Mr. J. D. Scott discussed retinal detachment surgery without drainage of fluid. Using silastic sponge plombage, he advocates that the implant should be radial to the limbus rather than circumferential, to avoid the danger of that the retinal hole will gape.

Mr. R. F. Fisher showed that there is a relationship between lens fibre stress, as in accommodation, and lens opacity formation. 